\title{
Unexpected long-term changes in chromosome inversion frequencies in a Neotropical Drosophila species
}

\author{
Marcos R. D. Batista, Galina Ananina, Louis B. Klaczko* \\ Departamento de Genética, Evolução e Bioagentes, Instituto de Biologia, Universidade Estadual de Campinas, Campinas, \\ São Paulo, Brazil
}

\begin{abstract}
Several long-term studies on Drosophila chromosome inversion polymorphisms have shown that inversions can be a valuable tool to monitor rapid genetic shifts with climate change. However, so far, no study has assessed the effects of climate change in populations of Neotropical Drosophila species. After more than 2 decades, new samples were collected from the Parque Nacional do Itatiaia, Rio de Janeiro, to assess any changes in inversion frequencies and to detect possible global warming effects on the inversion polymorphism of the second chromosome of D. mediopunctata. Our results show unexpected simultaneous changes in inversion frequencies associated with climate change. Perhaps climatic variables other than temperature underlying the process caused such change, although potential genetic drift effects or demographic factors cannot be excluded. Further studies assessing population genetic structure may help clarify the changes observed.
\end{abstract}

KEY WORDS: Global warming · Chromosomal inversion · Brazilian Atlantic Forest · Temporal variation $\cdot$ Drosophila mediopunctata

\section{INTRODUCTION}

Climate change has affected global biota, producing rapid evolutionary responses (Parmesan 2006, Lavergne et al. 2010). Montane tropical biota are believed to be particularly vulnerable to global warming effects (Sheldon et al. 2011). Several longterm studies on Drosophila inversion polymorphisms have shown that changes in inversion frequencies can be a valuable tool to monitor rapid genetic shifts caused by climatic change (Stamenkovic-Radak et al. 2008, Balanyà et al. 2009, Levitan \& Etges 2009, Rodriguez-Trelles \& Rodriguez 2010; for review see: Hoffmann \& Rieseberg 2008 and Rezende et al. 2010). None of these studies, however, addresses the potential effects of climate change on a Drosophila Neotropical species.

Drosophila mediopunctata belongs to the tripunctata group in the subgenus Drosophila. This is the second largest Drosophila group from the Neotropical region, comprising 79 species (Yotoko et al. 2003, Hatadani et al. 2009, Bächli 2011).

This species has a wide distribution and has been reported in many regions in Brazil, such as the south where it is the most commonly collected species, and in other places of South and Central America, especially at high altitudes (Saavedra et al. 1995).

Drosophila mediopunctata is an almost exclusively forest dwelling species (rare or absent in Brazilian savannah [cerrado] and caatinga; see Tidon 2006, Mata et al. 2010). It has 5 pairs of acrocentric chromosomes and 1 pair of dot chromosomes that do not polytenize (Kastritsis 1966), and is highly polymorphic for chromosome inversions. The X chromosome has 3 inversions, one of which is related to the sex-ratio trait (Carvalho et al. 1989). Chromosome IV has 2 inversions, and chromosome II has 17 gene arrangements: 8 in the distal region (DA, DI, DP, DS, DV, etc.) and 9 
in the proximal region ( $\mathrm{PA} 0, \mathrm{~PB} 0, \mathrm{PC} 0, \mathrm{PC} 1$, etc.). There is strong linkage disequilibrium between inversions in the distal and proximal regions of the second chromosome. Among the 72 possible combinations of distal region and proximal inversions found (Peixoto \& Klaczko 1991, Ananina et al. 2002, Klaczko 2006), $90 \%$ of the total is represented by 5 haplotypes (DA-PA0, DI-PB0, DS-PC0, DP-PC0 and DV-PC0).

A natural population of Drosophila mediopunctata from the Parque Nacional do Itatiaia, Rio de Janeiro State, was investigated in the late 1980s, where an altitudinal cline was detected for morphological traits and inversion frequencies (Bitner-Mathé et al. 1995, Bitner-Mathé \& Klaczko 1999, Ananina et al. 2004). Moreover, the frequencies of inversions DA, DP and DS showed cyclical seasonal variation (Klaczko 2006). The frequency of DA (usually associated with proximal arrangement PA0) increased in cold dry months and decreased in warmer rainy months, while pooled frequencies of DP and DS (both associated with PC0) showed an opposite pattern. Consistently, this pattern was observed in an altitudinal cline in which the frequency of DA showed a significant positive correlation with altitude $(\mathrm{r}=0.87, \mathrm{p}<$ 0.01 ), while the pooled frequencies of DP and DS showed a highly significant yet negative correlation $(\mathrm{r}=-0.91, \mathrm{p}<0.001)$. Gene arrangement DI did not show any seasonal variation or correlation with either temperature or altitude. This pattern suggests that natural selection is maintaining the observed variation (Ananina et al. 2004, Klaczko 2006).

Hatadani \& Klaczko (2008) showed that Drosophila mediopunctata wing size and shape were influenced by second chromosome karyotype, sex, and temperature under controlled laboratory conditions. They also found evidence of interaction between karyotype and temperature on wing shape, suggesting the existence of genotype-environment interaction on this character, and that this interaction may be correlated with temperature differences across seasons. Thus, the genetic content of the inversions may have accumulated different alleles adapted to different temperatures. Similarly, Andrade et al. (2009) showed that different chromosome karyotypes affected not only wing shape, but also male genital (aedeagus) morphology.

After $>2$ decades, new collections were carried out at the Parque Nacional do Itatiaia in order to characterize long-term changes in inversion frequencies and to assess the possible effects from climatic change, in particular the potential impact of global warming on the inversion polymorphism of the second chromosome. We tested the hypothesis that, after 2 decades, inversions associated with hot-rainy weather (DS and DP) increased in frequency at the expense of DA (DA being the inversion correlated with cold-dry climate conditions).

\section{MATERIALS AND METHODS}

\subsection{Drosophila mediopunctata samples}

Between June 2007 and August 2010, 7 field trips were carried out in the Parque Nacional do Itatiaia, Rio de Janeiro, Brazil $\left(22^{\circ} 26^{\prime} \mathrm{S}, 44^{\circ} 37^{\prime} \mathrm{W}\right)$. Our collection strategy was designed to test the following hypotheses: (1) if the current overall frequency of gene arrangements was similar to those previously described by Ananina et al. (2004), and if the overall correlations with environmental variables were still valid; we sampled different altitudinal points varying among a total of 9 points (from 590 to $1190 \mathrm{~m}$ above sea level, a.s.l., see Table A1 in Appendix 1) in each of the 7 collections in different seasons; (2) if gene arrangements DA, DS and DP were still significantly associated to altitude; we sampled fly populations from 7 different altitudes (from 590 to $1190 \mathrm{~m}$ a.s.l., Table A1) on one single occasion (cold-dry season 2009); and (3) if gene arrangements DA, DS and DP were still cycling seasonally; 2 areas (sites at altitudes of 750 and $950 \mathrm{~m}$ a.s.l.) were sampled on each of the 7 collecting dates to avoid confounding the effects of seasonal cycling and clinal variation of the inversion frequencies.

Flies were collected over fermented banana baits with entomological nets. They were then taken to the laboratory for analysis.

\subsection{Cytological procedures and statistical analysis}

Inversion frequency distributions were estimated using the 'egg sample' and 'male' methods (Arnold 1981, Ananina et al. 2004). Wild caught males were individually crossed with 3 virgin females from the ITC-229-ET homokaryotypic strain, maintained at $16.5^{\circ} \mathrm{C}$ and reared on trimeveledon culture medium (whole wheat flour, yeast, agar, sugar and powdered milk, see Carvalho et al. 1989). From each cross, up to 8 F1 larvae were karyotyped to infer the male parent karyotype, which was used to estimate inversion frequencies. The polytene salivary gland chromosomes of third instar larvae were prepared with $1 \mathrm{~N}$ $\mathrm{HCl}_{\text {, }}$ and subsequently stained with lacto-acetic- 
orcein, as described by Ashburner (1989). For the 'egg sample' method, one F1 larvae from each wild caught female was analyzed and the observed karyotype used to estimate the inversion frequencies. For each collection, the estimates of the 2 methods were compared with a chi-square test (Table A2). Since no case of significant difference was found, the frequencies were pooled. We must note that when the number of individuals in one of the sexes was $<5$, we did not test the differences; however, no relevant difference could be seen by visual inspection (data not shown).

In 2009, during the fall collection, altitude was measured with a GPS navigation device (Table A1). Climatic variables were obtained from Resende Automatic Station; available data can be found at www.agritempo.gov.br (accessed May 10, 2011). For the analysis, the frequency of the arrangement DV was pooled with the frequencies of DS and DP, since they are all preferentially associated with PC0.

We compared the inversion frequencies with those previously published (Peixoto \& Klaczko 1991, Ananina et al. 2004) using a chi-square test (Zar 2010). Pearson's correlation tests were performed to assess associations between inversion frequencies (after angular transformation, Zar 2010) and geographical as well as climatic variables including altitude, temperature and precipitation.

\section{RESULTS}

\subsection{Long-term variation of the climatic variables}

Fig. 1 shows the long-term variation for the maximum, minimum and mean temperatures over the last 3 decades. Positive and significant correlations between years and mean as well as minimum temperatures were observed $\left(T_{\text {mean }}: \mathrm{r}=0.46, \mathrm{p}=0.0195\right.$; $T_{\min }: r=0.62, p=0.0009$ ). Fig. 2 shows a marginally significant trend of decreasing annual precipitation in the region $(\mathrm{r}=-0.399, \mathrm{p}=0.048)$. If we remove the outlier years 2006 and 2007 from the analysis, however, temporal changes in precipitation are no longer significant $(\mathrm{r}=0.318, \mathrm{p}=0.130)$.

\subsection{Temporal variation of the inversion frequencies}

Table A1 shows second chromosome inversion frequencies on different collecting dates at different altitudinal sites. Current average second chromosome

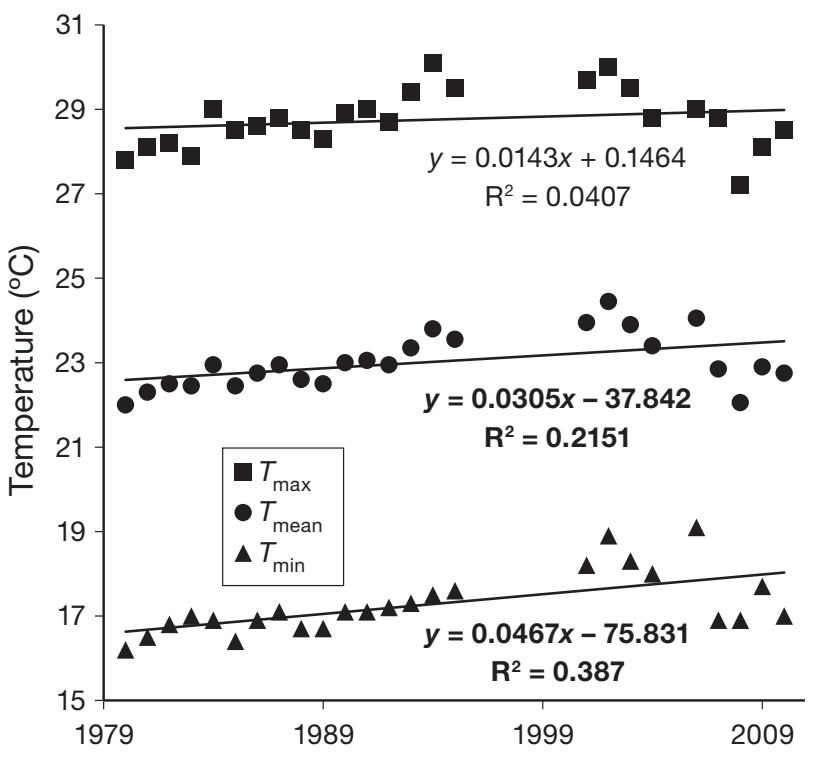

Fig. 1. Long-term temperature variations at Parque Nacional do Itatiaia, Rio de Janeiro. Annual means of average monthly maximum $\left(T_{\max }\right)$ and minimum $\left(T_{\min }\right)$ temperatures; $T_{\text {mean }}$ : mean of $T_{\max }$ and $T_{\min }$. Coefficients of determination $\left(\mathrm{R}^{2}\right)$ and equations in bold are significant at $5 \%$ level

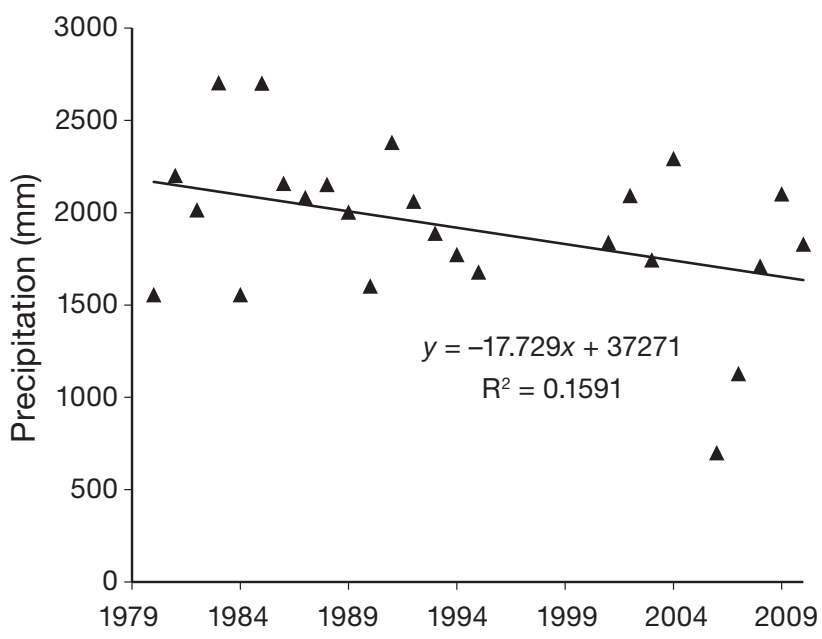

Fig. 2. Long-term variation of precipitation (annual sum of precipitation) at Parque Nacional do Itatiaia, Rio de Janeiro

inversion frequencies (Table 1) were significantly different from those in 1986 to $1988\left(X^{2}=74.97, p<\right.$ 0.001). Unexpectedly, increases of DA and especially of DI frequencies, as well as a decrease in the frequencies of DS, DP and DV, were significant (Fig. 3).

Furthermore, we compared the average frequency estimates for 2 different seasons: cold and dry (collections performed during fall and winter); hot and rainy (collections performed during spring and summer). To avoid confounding the effects of altitudinal clines 
Table 1. Drosophila mediopunctata. Chromosome II inversion frequencies $(\%)$ of $D$. mediopunctata averaged over seasons (data only from 750 and $950 \mathrm{~m}$ altitude areas) and overall average for the 7 collections (overall frequency: data pooled from all areas sampled) at Parque Nacional do Itatiaia, Rio de Janerio. $2 \mathrm{~N}$ : number of chromosomes analyzed.

OT: rare arrangements (DJ, DR, DT)

\begin{tabular}{|lccc|}
\hline Inversions & $\begin{array}{c}\text { Hot-rainy } \\
\text { season (\%) }\end{array}$ & $\begin{array}{c}\text { Cold-dry } \\
\text { season (\%) }\end{array}$ & $\begin{array}{c}\text { Overall } \\
\text { frequency (\%) }\end{array}$ \\
\hline DA & 46.3 & 57.0 & 54.8 \\
DI & 29.3 & 29.9 & 29.5 \\
DS & 13.0 & 4.1 & 7.5 \\
DP & 4.9 & 2.9 & 2.7 \\
DV & 4.9 & 4.5 & 4.0 \\
OT & 1.5 & 1.6 & 1.5 \\
2N & 324 & 314 & 1178 \\
\hline
\end{tabular}

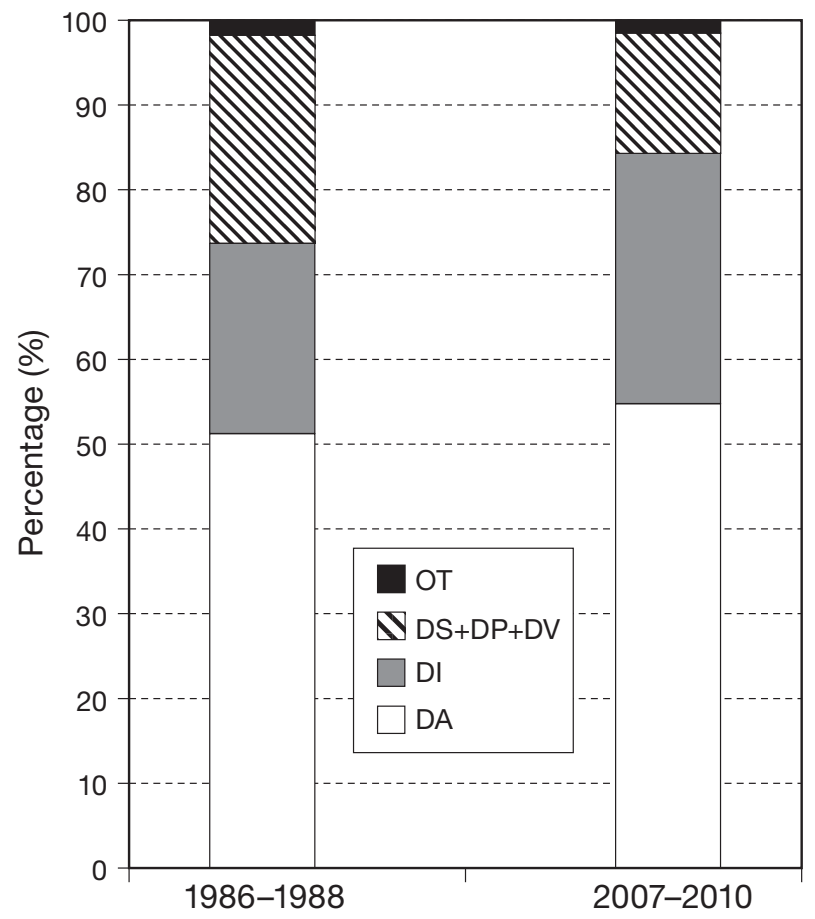

Fig. 3. Drosophila mediopunctata. Comparison between current (2007-2010) and previous (1986-1988) average frequencies of $D$. mediopunctata second chromosome inversions. OT: rare arrangements (DJ, DR, DT)

with seasonal effects, only data from population samples at 950 and $750 \mathrm{~m}$ were considered, since these populations were collected in every field trip. Fig. 4 shows that the frequencies of DA and the combined frequencies of DS + DP + DV continued to show seasonal variation as previously described in Ananina et al. (2004). Also, DI did not show any noticeable seasonal variation as previously described (Figs. 3 \& A1).

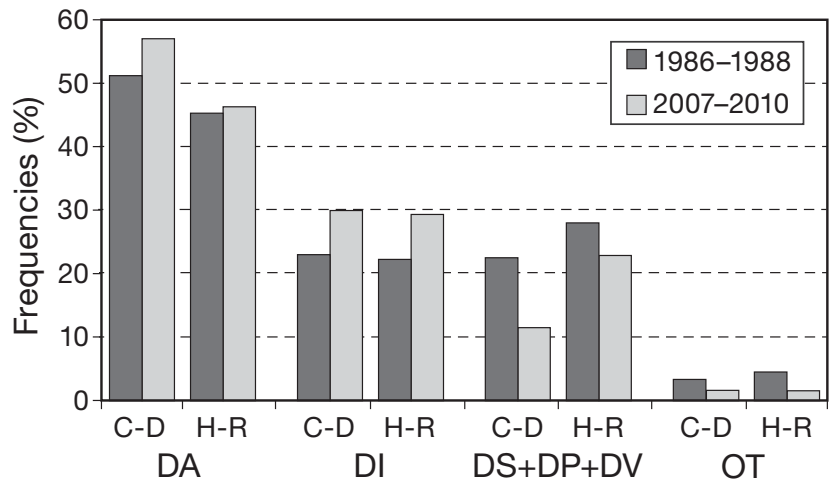

Fig. 4. Drosophila mediopunctata. Seasonal cycle of inversion frequencies (\%) at Parque Nacional do Itatiaia, Rio de Janeiro. Only data from areas at 950 and $750 \mathrm{~m}$ were considered, since they covered the entire seasonal cycle. C-D: cold-dry season; H-R: hot-rainy season

\subsection{Clines and correlations}

To assess if previously described altitudinal clines were still present in these populations, we calculated correlations of inversion frequencies with altitudes from a single collecting date: fall 2009 (Fig. 5). The DA gene arrangement no longer showed a significant correlation with altitude $(\mathrm{r}=-0.12, \mathrm{p}=0.78)$, but DS continued to show a significant negative correlation $(r=-0.71, p<0.05)$ as previously found. Since DP is now found in low frequencies, we pooled the data for inversions DS, DP and DV, consistently finding a significant and negative correlation with altitude $(r=-0.82, p=0.013)$. Surprisingly, we also observed a positive and significant correlation between DI and altitude $(r=0.75, p=0.032)$.

Correlations between inversion frequencies and temperature as well as precipitation data from the Resende climatic station (Table 2) were consistent with previous results (Ananina et al. 2004): DA was negatively correlated with temperature (but no longer significant: $r=-0.55, p=0.20$ ), as was precipitation (close to but not significant: $\mathrm{r}=-0.74, \mathrm{p}=$ 0.055 ). While DS was positively and significantly correlated with these variables (temperature: $r=0.756$, $\mathrm{p}=0.049$; precipitation: $\mathrm{r}=0.797, \mathrm{p}=0.032$ ), no significant correlations were detected between DI and these climatic variables.

\section{DISCUSSION}

The observed overall climatic changes in the region of the Parque Nacional do Itatiaia were consistent with the effects of global warming as considered by the Intergovernmental Panel on Climate Change 

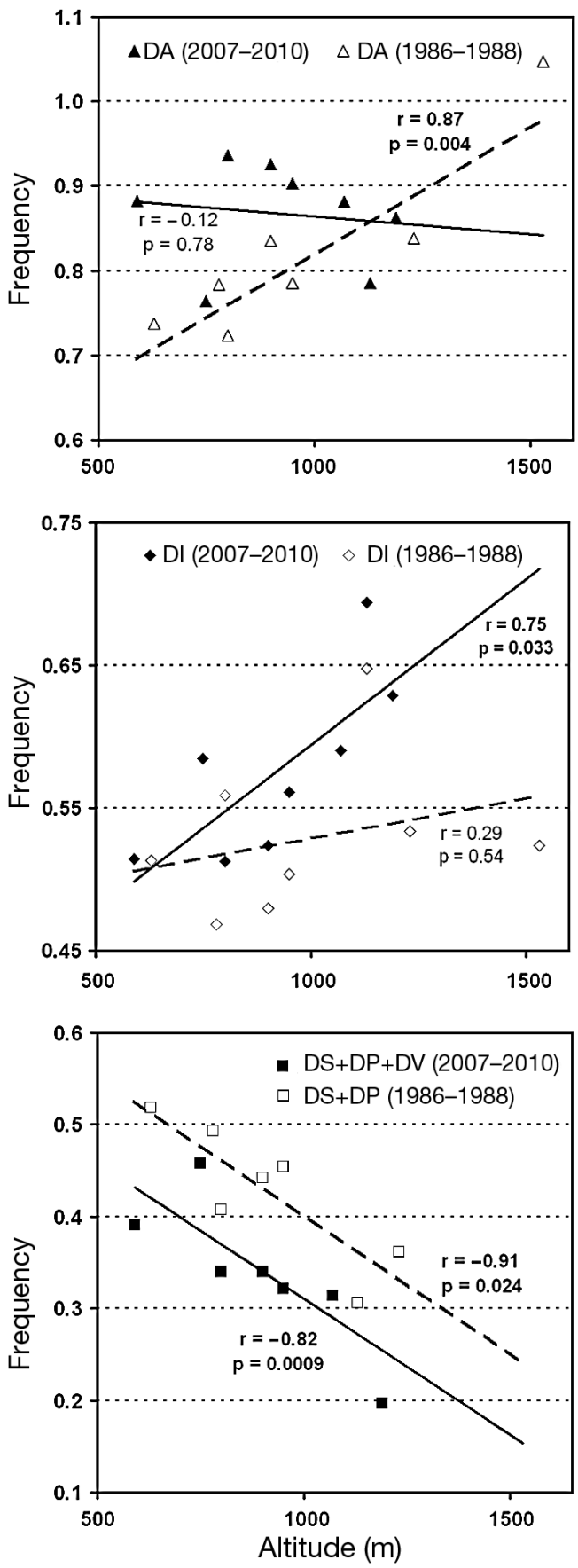

Fig. 5. Drosophila mediopunctata. Altitudinal variation in chromosomal inversion frequencies (proportions after angular transformation). Solid lines: fall 2009 collection; dashed lines: previous collections pooled (1986-1988); frequencies of DA (trangles), DI (diamonds), DS+DP+DV (squares). Pearson's correlation coefficients ( $r$ ) and $p$-values in bold are significant at $5 \%$ level

(IPCC 2007). There was a clear trend in the increasing averages of minimum temperatures; although this was not apparent for maximum temperatures (Easterling et al. 1997).
Table 2. Drosophila mediopunctata. Pearson's correlation (r) between inversion frequencies and different climatic variables. * Significant correlations. OT: rare arrangements (DJ, DR, DT)

\begin{tabular}{|lcccc|}
\hline Inversions & \multicolumn{2}{c}{ Temperature } & \multicolumn{2}{c|}{ Precipitation } \\
& $\mathrm{r}$ & $\mathrm{p}$ & $\mathrm{r}$ & $\mathrm{p}$ \\
\hline & & & & \\
DA & -0.548 & 0.202 & -0.744 & 0.055 \\
DI & -0.390 & 0.386 & 0.076 & 0.871 \\
DS & 0.756 & $0.049^{*}$ & 0.796 & $0.032^{*}$ \\
DS + DP + DV & 0.725 & 0.065 & 0.748 & 0.053 \\
OT & 0.355 & 0.434 & -0.101 & 0.829 \\
\hline
\end{tabular}

Long-term analyses of chromosomal inversion polymorphisms in different Drosophila species have shown changes in inversion frequencies associated with recent climate change, suggesting that widespread species may undergo adaptive shifts in response to global warming (Hoffmann \& Rieseberg 2008). In Australian D. melanogaster populations, the In(3R)Payne inversion increased in frequency near the equator, forming a latitudinal cline (Knibb et al. 1981). After $\sim 20 \mathrm{yr}$, Anderson et al. (2005) and Umina et al. (2005) showed frequency increase in this inversion in all Australian populations, suggesting that this was a direct response to global warming.

In Drosophila robusta, arrangements more frequent in northern regions for different North American populations decreased in frequency while 'southern' gene arrangements increased in frequency over the last 20 yr (Etges \& Levitan 2008, Levitan \& Etges 2009). Rodríguez-Trelles \& Rodríguez (1998) showed O chromosomal arrangement frequency changes in populations of $D$. subobscura with temporal increases of southern arrangement frequencies. Further, Balanyà et al. (2006) showed that $D$. subobscura populations from 3 different continents evolved similar patterns in response to the impact of global warming. Stamenkovic-Radak et al. (2008) observed unexpected shifts in the chromosome polymorphism of $D$. subobscura where the appearance and stable maintenance of complex gene arrangements were attributed to reduced effective population sizes.

However, long-term temporal changes in inversion frequencies have not been observed in all species studied. North American populations of Drosophila pseudoobscura showed no consistent variation over $60 \mathrm{yr}$ (Schaeffer 2008 and citations therein); although Schaeffer (2008) pointed out that in populations from California: 'one can speculate that environmental changes were brought on by changes in agricultural 
practice, in pesticide use, in air pollution, or global warming'. Similarly, Indian populations of $D$. ananassae have not shown any temporal variation in $20 \mathrm{yr}$ of monitoring chromosomal inversion frequencies (Singh \& Singh 2007).

In Itatiaia populations of Drosophila mediopunctata, the DI gene arrangement showed significant temporal changes in frequency. The frequency increased nearly $7 \%$ from the previous (1986-88 collections) $22.4 \%$, as opposed to DS, DP and DV, which decreased $\sim 10 \%$ from the previous $24.5 \%$ (Ananina et al. 2004). This is an unexpected result, as DS and DP gene arrangements previously showed a positive correlation with temperature, while the gene arrangement DI was not correlated to temperature (Table 2; Ananina et al. 2004).

Santos et al. (2005) showed that the chromosomal inversion polymorphism of Drosophila subobscura favored at high laboratory temperatures was not necessarily the same as the most common arrangements in populations of $D$. subobscura at warmer latitudes. This may be taken as evidence that the factors associated with genetic shifts might be more complex than a simple environmental variable and, perhaps, other underlying biotic and abiotic factors might be at work independently or interacting with each other, thus influencing inversion frequencies.

Ananina et al. (2004) also described altitudinal clines for DA, DS and DP, in which DA increased in frequency in higher altitudinal populations; however, DS and DP showed a contrary pattern. After 2 decades, DS, DP, DV maintained the same pattern with a highly significant negative correlation with altitude. The DI inversion, on the other hand, showed a significant positive altitudinal cline, while DA was not correlated with altitude (Fig. 5). These puzzling findings must be further investigated.

In contrast, seasonal variation of the gene arrangements was still present in our most recent collections. Inversion DA continues to show seasonal variation, increasing in frequency in the cold and dry season, while DS, DP and DV decreased in frequency. Repeated seasonal cycles of changes in inversions frequencies provide the clearest and least equivocal evidence of strong selection acting on inversion polymorphism in natural populations (Krimbas \& Powell 1992, Powell 1997). Bradshaw \& Holzapfel (2008) suggested that consequences of climate change will be longer warm seasons and shorter winters, causing phenological shifts in temperate zone organisms. Such shifts may have greater genetic consequences from factors other than merely temperature changes. Climate change in the neotropical region involves warmer and drier winters and hotter summers with torrential rains influenced by other climatic phenomena such as 'El Niño' (Ab'Saber 2009). Nevertheless, these changes in climate seem to have had little effect on the seasonal cycles of Drosophila mediopunctata gene arrangement frequencies.

The observed changes in Drosophila mediopunctata chromosomal inversion frequencies over the last 20 yr may reflect responses to (1) climatic changes of abiotic factors, e.g. temperature, humidity, etc. (Chown et al. 2011); (2) changes in flora and fauna composition (Lavergne et al. 2010, Sheldon et al. 2011) as a result of an improvement of public policies toward park preservation; and climatic changes, such as global warming, affecting the distribution of species along the elevation gradient and, consequently, the community structure (driven by competition and predation); (3) changes in the genetic content of each inversion; (4) modifications of the demographic structure of the population with a possible effect of genetic drift (Stamenkovic-Radak et al. 2008, Joubert \& Bijlsma 2010, Hoffmann \& Sgrò 2011).

Our results show that the chromosome polymorphism of Drosophila mediopunctata changed in unexpected ways over the last $25 \mathrm{yr}$ concomitant with climate change in the region of Parque Nacional do Itatiaia. Moreover, these observed changes in climate may have affected morphological traits in these populations; whether these changes were consistent with previous observations (Bitner-Mathé et al. 1995, Bitner-Mathé \& Klaczko 1999) remains an unresolved issue. Further studies assessing the geographical variation and the genetic structure of the population using molecular markers may aid in clarifying the observed pattern.

Acknowledgements. We thank Dr. L. Nascimento, Coordenador de Pesquisa do Parque Nacional do Itatiaia for the authorizations and hospitality at the Park and J. Bernardino for his help with the field work. We appreciate the technical help of M. S. Couto and C. Couto. We are also grateful for assistance from A. B. Martins, D. Moraes, F. Rocha, I. M. Ventura, K. A. de Carvalho and R. Cavasini on different collecting occasions. We appreciate the dedicated work of F. M. Boschiero of the Espaço da Escrita from CGU-Unicamp for the careful revision of the English version. Special thanks to 2 anonymous reviewers who gave valuable and careful suggestions that improved the paper, as well as E. and R. Hogan for correcting the English version of the final manuscript. Finally, we thank Coordenação de Aperfeiçoamento de Pessoal de Nível Superior (CAPES), Conselho Nacional de Desenvolvimento Científico e Tecnológico (CNPq), Fundação de Amparo ao Ensino e Pesquisa (FAEP-Unicamp) and Fundação de Amparo à Pesquisa do Estado de São Paulo (FAPESP) for financial support. 


\section{LITERATURE CITED}

Ab'Saber AN (2009) A propósito da periodicidade climatohidrológica que vem provocando grandes crises em Santa Catarina. Estud Avançados 23:297-306

Ananina G, Souza WN, Peixoto AA, Klaczko LB (2002) Polytene chromosome map and inversion polymorphism in Drosophila mediopunctata. Mem Inst Oswaldo Cruz 97: 691-694

Ananina G, Peixoto AA, Blanche-Mathé BC, Souza WN, da Silva LB, Valente VLS, Klaczko LB (2004) Chromosomal inversion polymorphism in Drosophila mediopunctata: seasonal, altitudinal and latitudinal variation. Genet Mol Biol 27:61-69

Anderson AR, Hoffmann AA, McKechnie SW, Umina PA, Weeks AR (2005) The latitudinal cline in the In(3R)Payne inversion polymorphism has shifted in the last 20 years in Australian Drosophila melanogaster populations. Mol Ecol 14:851-858

Andrade CAC, Vieira RD, Ananina G, Klaczko LB (2009) Evolution of the male genitalia: morphological variation of the aedeagi in a natural population of Drosophila mediopunctata. Genetica 135:13-23

Arnold SJ (1981) Statistics of natural populations. I. Estimating an allele probability in cryptic fathers with a fixed number of offspring. Biometrics 37:495-504

Ashburner M (1989). Drosophila: a laboratory manual. CSHL Press, Cold Spring Harbor, NY

Bächli (2011) Taxodros: database 2010-12, v1.03, available at www.taxodros.uzh.ch (accessed April 06, 2011)

> Balanyà J, Oller JM, Huey RB, Gilchrist GW, Serra L (2006) Global genetic change tracks global climatic warning in Drosophila subobscura. Science 313:1773-1775

Balanyà J, Huey RB, Gilchrist GW, Serra L (2009) The chromosomal polymorphism of Drosophila subobscura: a microevolutionary weapon to monitor global change. Heredity 103:364-367

- Bitner-Mathé BC, Klaczko LB (1999) Size and shape heritability in natural populations of Drosophila mediopunctata: temporal and microgeographical variation. Genetica 105:35-42

Bitner-Mathé BC, Peixoto AA, Klaczko LB (1995) Morphological variation in a natural population of Drosophila mediopunctata: altitudinal cline, temporal changes and influences of chromosome inversions. Heredity 75:54-61

- Bradshaw WE, Holzapfel CM (2008) Genetic response to rapid climate change: it's seasonal timing that matters. Mol Ecol 17:157-166

Carvalho AB, Peixoto AA, Klaczko LB (1989) 'Sex-ratio' in Drosophila mediopunctata. Heredity 62:425-428

> Chown SL, Sorensen JG, Terblanche JS (2011) Water loss in insects: an environmental change perspective. J Insect Physiol 57:1070-1084

Easterling DR, Horton B, Jones PD, Peterson TC and others (1997) Maximum and minimum temperature trends for the globe. Science 277:364-367

Etges WJ, Levitan M (2008) Variable evolutionary response to regional climate change in a polymorphic species. Biol J Linn Soc 95:702-718

> Hatadani LM, Klaczko LB (2008) Shape and size variation on the wing of Drosophila mediopunctata: influence of chromosome inversions and genotype-environment interaction. Genetica 133:335-342

> Hatadani LM, McInerney JO, Medeiros HF, Junqueira ACM, Azeredo-Espin AM, Klaczko LB (2009) Molecular phylo- geny of the Drosophila tripunctata and related groups (Diptera: Drosophilidae). Mol Phylogenet Evol 51:595-600

Hoffmann AA, Rieseberg LH (2008) Revisiting the impact of inversions in evolution: from population genetic markers to drivers of adaptive shifts and speciation? Annu Rev Ecol Evol Syst 39:21-42

Hoffmann AA, Sgrò CM (2011) Climate change and evolutionary adaptation. Nature 470:479-485

Intergovernmental Panel on Climate Change (IPCC) (2007). Climate change 2007: the physical science basis. In: Solomon S, Qin D, Manning M, Chen Z and others (eds) Contribution of Working Group I to the Fourth Assessment Report of the Intergovernmental Panel on Climate Change. Cambridge University Press, Cambridge

Joubert D, Bijlsma R (2010) Interplay between habitat fragmentation and climate change: inbreeding affects the response to thermal stress in Drosophila melanogaster. Clim Res 43:57-70

Kastritsis CD (1966). Cytological studies of some species of the tripunctata group of Drosophila. Univ Texas Publ 6615:413-474

- Klaczko LB (2006) Evolutionary genetics of Drosophila mediopunctata. Genetica 126:43-55

Knibb WR, Oakeshott JG, Gibbs J (1981) Chromosome inversion polymorphisms in Drosophila melanogaster. I. Geographic clines and climatic associations in Australasian populations. Genetics 98:833-847

Krimbas CB, Powell JR (1992). Drosophila inversion polymorphism. CRC Press, Boca Raton, FL

> Lavergne S, Mouquet N, Thuiller W, Ronce O (2010) Biodiversity and climate change: integrating evolutionary and ecological responses of species and communities. Annu Rev Ecol Evol Syst 41:321-350

Levitan M, Etges WJ (2009) Rapid response to perturbation of chromosome frequencies in natural populations of Drosophila robusta. Genetica 137:1-8

> Mata RA, McGeoch MA, Tidon R (2010) Drosophilids (Insecta, Diptera) as tools for conservation biology. Nat Conservação 8:60-65

> Parmesan C (2006) Ecological and evolutionary responses to recent climate change. Annu Rev Ecol Evol Syst 37: $637-669$

Peixoto AA, Klaczko LB (1991) Linkage disequilibrium analysis of chromosomal inversion polymorphism in Drosophila. Genetics 129:773-777

Powell JR (1997). Progress and prospects in evolutionary biology: the Drosophila model. Oxford University Press, New York, NY

Rezende EL, Balanyà J, Rodriguez-Trelles F, Rego C and others (2010) Climate change and chromosomal inversions in Drosophila subobscura. Clim Res 43:103-114

Rodríguez-Trelles F, Rodríguez MA (1998) Rapid microevolution and loss of chromosomal diversity in Drosophila in response to climate warming. Evol Ecol 12:829-838

> Rodriguez-Trelles F, Rodriguez MA (2010) Measuring evolutionary responses to global warming: cautionary lessons from Drosophila. Insect Conserv Diversity 3:44-50

Saavedra CC, Callegari-Jacques SM, Napp M, Valente VLS (1995) A descriptive and analytical study of Neotropical drosophilid communities. J Zoological Syst Evol Res 33: 62-74

Santos M, Cespedes W, Balanyà J, Trotta V, Calboli FCF, Fontdevila A, Serra L (2005) Temperature-related genetic changes in laboratory populations of Drosophila subobscura: evidence against simple climatic-based expla- 
nations for latitudinal clines. Am Nat 165:258-273

Schaeffer SW (2008) Selection in heterogeneous environments maintains the gene arrangement polymorphism of Drosophila pseudoobscura. Evolution 62:3082-3099

Sheldon KS, Yang S, Tewksbury JJ (2011) Climate change and community disassembly: impacts of warming on tropical and temperate montane community structure. Ecol Lett 14:1191-1200

Singh P, Singh BN (2007) Population genetics of Drosophila ananassae: genetic differentiation among Indian natural populations at the level of inversion. Genet Res 89: 191-199

Stamenkovic-Radak M, Rasic G, Savic T, Kalajdzic P, Kurbalija Z, Kenig B, Andjelkovic M (2008) Monitoring of the genetic structure of natural populations: change of the effective population size and inversion polymorphism in Drosophila subobscura. Genetica 133:57-63

Tidon R (2006) Relationships between drosophilids (Diptera, Drosophilidae) and the environment on two contrasting tropical vegetations. Biol J Linn Soc 87:233-248

Umina PA, Weeks AR, Kearney MR, McKechnie SW, Hoffmann AA (2005) A rapid shift in a classic clinal pattern in Drosophila reflecting climate change. Science 308: 691-693

Yotoko KSC, Medeiros HF, Solferini VN, Klaczko LB (2003) A molecular study of the systematics of the Drosophila tripunctata group and the tripunctata radiation. Mol Phylogenet Evol 28:614-619

Zar JH (2010) Biostatistical analysis, 5th edn. Prentice Hall, Upper saddle River, NJ

\section{Appendix 1}

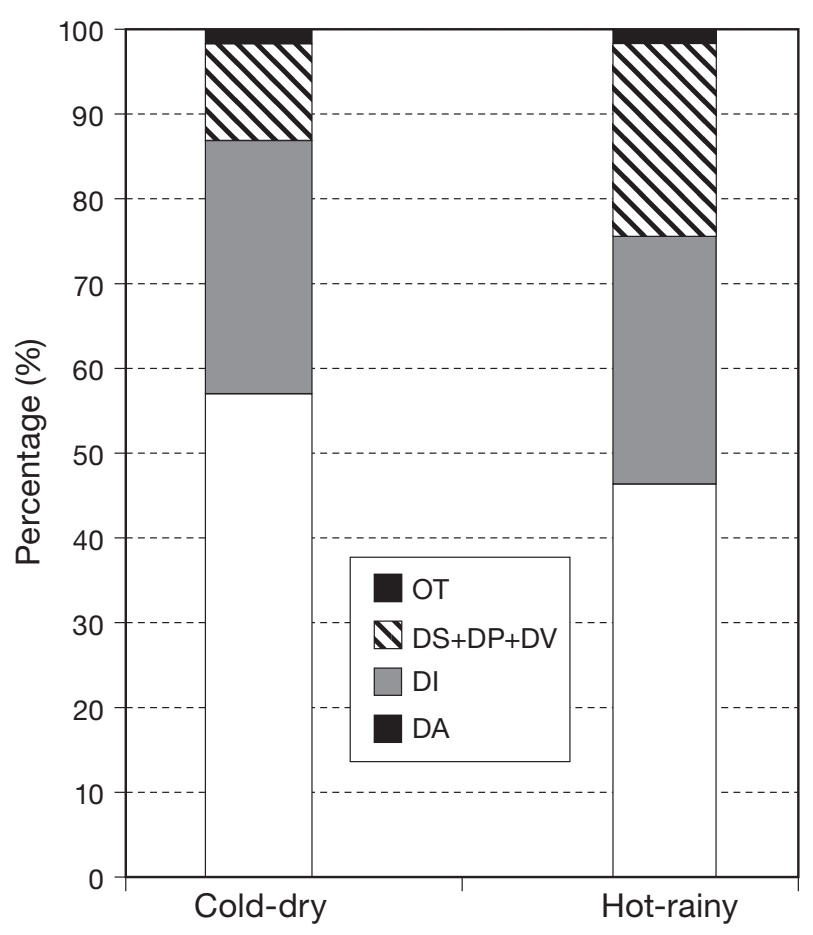

Fig. A1. Drosophila mediopunctata. Comparison between current inversion frequencies (2007-2010) contrasting colddry and hot-rainy seasons, considering only frequencies obtained at 2 altitudes: 750 and $950 \mathrm{~m}$. OT: rare arrangements 
Table A1. Drosophila mediopunctata. Second chromosome inversion frequencies (\%) of $D$. mediopunctata from 7 collections at sites with different altitudes (m), at Parque Nacional do Itatiaia, Rio de Janeiro. 2N: number of chromosomes analyzed; C-D: cold-dry season; H-R: hot-rainy season. Inv: Inversions;

OT: rare arrangements; $2 \mathrm{~N}$ : number of chromosomes analyzed

\begin{tabular}{|c|c|c|c|c|c|c|c|c|c|c|}
\hline Inv & 1190 & 1130 & 1100 & 1070 & 950 & 900 & 800 & 750 & 590 & Total \\
\hline \multicolumn{11}{|c|}{ June $1-4,2007 ;$ C-D } \\
\hline DA & & & 66.7 & & 52.9 & & & 57.1 & & 57.4 \\
\hline DI & & & 33.3 & & 41.2 & & & 35.7 & & 37.2 \\
\hline DS & & & 0 & & 2.9 & & & 2.4 & & 2.1 \\
\hline DP & & & 0 & & 0 & & & 0 & & 0 \\
\hline DV & & & 0 & & 2.9 & & & 4.8 & & 3.2 \\
\hline OT & & & 0 & & 0 & & & 0 & & 0 \\
\hline $2 \mathrm{~N}$ & & & 18 & & 34 & & & 42 & & 94 \\
\hline \multicolumn{11}{|c|}{ February $22-26,2008 ;$ H-R } \\
\hline DA & & & 41.7 & & 31.8 & & & 52.6 & & 44.4 \\
\hline DI & & & 41.7 & & 40.9 & & & 26.3 & & 33.3 \\
\hline DS & & & 8.3 & & 18.2 & & & 18.4 & & 16.7 \\
\hline DP & & & 8.3 & & 4.5 & & & 0 & & 2.8 \\
\hline DV & & & 0 & & 4.5 & & & 2.6 & & 2.8 \\
\hline OT & & & 0 & & 0 & & & 0 & & 0 \\
\hline $2 \mathrm{~N}$ & & & 12 & & 22 & & & 38 & & 72 \\
\hline \multicolumn{11}{|c|}{ November 19-24, 2008; H-R } \\
\hline DA & & & 65.2 & & 48.4 & & & 44 & & 53.3 \\
\hline DI & & & 29.3 & & 25 & & & 29.8 & & 28.3 \\
\hline DS & & & 0 & & 12.5 & & & 14.3 & & 8.3 \\
\hline DP & & & 0 & & 6.3 & & & 7.1 & & 4.2 \\
\hline DV & & & 3.3 & & 6.3 & & & 2.4 & & 3.8 \\
\hline OT & & & 2.2 & & 1.6 & & & 2.4 & & 2.1 \\
\hline $2 \mathrm{~N}$ & & & 92 & & 64 & & & 84 & & 240 \\
\hline \multicolumn{11}{|c|}{ March 10-16, 2009; H-R } \\
\hline DA & & & 46.7 & & 43.8 & & & 35.4 & & 40.4 \\
\hline DI & & & 30 & & 25 & & & 33.3 & & 30.9 \\
\hline DS & & & 16.7 & & 6.3 & & & 14.6 & & 13.8 \\
\hline DP & & & 0 & & 6.3 & & & 8.3 & & 5.3 \\
\hline DV & & & 3.3 & & 6.3 & & & 8.3 & & 6.4 \\
\hline OT & & & 3.3 & & 12.5 & & & 0 & & 3.2 \\
\hline $2 \mathrm{~N}$ & & & 30 & & 16 & & & 48 & & 94 \\
\hline \multicolumn{11}{|c|}{ May 30-June 5, 2009; C-D } \\
\hline DA & 57.7 & 50 & & 59.5 & 61.7 & 63.9 & 64.8 & 47.8 & 59.7 & 58.9 \\
\hline DI & 34.6 & 40.9 & & 31 & 28.3 & 25 & 24.1 & 30.4 & 24.2 & 28.4 \\
\hline DS & 0 & 0 & & 7.1 & 5 & 5.6 & 5.6 & 6.5 & 6.5 & 5.2 \\
\hline DP & 3.8 & 0 & & 2.4 & 1.7 & 0 & 1.9 & 4.3 & 3.2 & 2.3 \\
\hline DV & 0 & 9.1 & & 0 & 3.3 & 5.6 & 3.7 & 8.7 & 4.8 & 4.3 \\
\hline OT & 3.8 & 0 & & 0 & 0 & 0 & 0 & 2.2 & 1.6 & 0.9 \\
\hline $2 \mathrm{~N}$ & 26 & 22 & & 42 & 60 & 36 & 54 & 46 & 62 & 348 \\
\hline \multicolumn{11}{|c|}{ March 3-5, 2010; H-R } \\
\hline DA & 0 & 58.8 & & 54.8 & 59.4 & 66.7 & & 60 & & 58.2 \\
\hline DI & 0 & 23.5 & & 26.2 & 34.4 & 16.7 & & 20 & & 26.1 \\
\hline DS & 0 & 8.8 & & 9.5 & 3.1 & 16.7 & & 10 & & 8.2 \\
\hline DP & 0 & 0 & & 0 & 0 & 0 & & 0 & & 0 \\
\hline DV & 0 & 5.9 & & 4.8 & 3.1 & 0 & & 10 & & 5.2 \\
\hline OT & 0 & 2.9 & & 4.8 & 0 & 0 & & 0 & & 2.2 \\
\hline $2 \mathrm{~N}$ & & 34 & & 42 & 32 & 6 & & 20 & & 134 \\
\hline \multicolumn{11}{|c|}{ August 23-27, 2010; C-D } \\
\hline DA & & & & 51.9 & 64 & & & 50 & 40 & 56.1 \\
\hline DI & & & & 38.9 & 19.8 & & & 37 & 30 & 29.6 \\
\hline DS & & & & 7.4 & 3.5 & & & 4.3 & 30 & 6.1 \\
\hline DP & & & & 1.9 & 5.8 & & & 2.2 & 0 & 3.6 \\
\hline DV & & & & 0 & 3.5 & & & 4.3 & 0 & 2.6 \\
\hline OT & & & & 0 & 3.5 & & & 2.2 & 0 & 2 \\
\hline $2 \mathrm{~N}$ & & & & 54 & 86 & & & 46 & 10 & 196 \\
\hline
\end{tabular}


Table A2. Drosophila mediopunctata. Number of flies analyzed at different altitudes (Alt) on each collection occasion. $\mathrm{N}$ : number of female (o) and male $\left(\sigma^{7}\right)$ adults karyotyped; Seasons - C-D: cold-dry; H-R: hot-rainy. All $\chi^{2}$ values are non-significant $(p>0.05)$. Tests were carried out only for samples where the number of males and females was $>5$

\begin{tabular}{|c|c|c|c|c|c|}
\hline Collections & Alt (m) & ${ }^{1}$ & $0^{1}$ & df & $\chi^{2}$ \\
\hline June 1-4, 2007; C-D & $\begin{array}{c}1100 \\
950 \\
750\end{array}$ & $\begin{array}{c}4 \\
10 \\
4\end{array}$ & $\begin{array}{c}5 \\
7 \\
30\end{array}$ & 1 & 2.84 \\
\hline February 22-26, 2008; H-R & $\begin{array}{c}1100 \\
950 \\
750\end{array}$ & $\begin{array}{c}4 \\
11 \\
16\end{array}$ & $\begin{array}{l}4 \\
0 \\
3\end{array}$ & & \\
\hline November 19-24, 2008; H-R & $\begin{array}{c}1100 \\
950 \\
750\end{array}$ & $\begin{array}{l}30 \\
20 \\
20\end{array}$ & $\begin{array}{l}32 \\
12 \\
22\end{array}$ & $\begin{array}{l}1 \\
1 \\
2\end{array}$ & $\begin{array}{l}0.16 \\
0.06 \\
4.53\end{array}$ \\
\hline March 10-16, 2009; H-R & $\begin{array}{c}1100 \\
950 \\
750\end{array}$ & $\begin{array}{l}0 \\
0 \\
0\end{array}$ & $\begin{array}{c}15 \\
8 \\
24\end{array}$ & & \\
\hline May 30-June 5, 2009; C-D & $\begin{array}{c}1190 \\
1130 \\
1070 \\
950 \\
900 \\
800 \\
750 \\
590\end{array}$ & $\begin{array}{c}3 \\
5 \\
6 \\
9 \\
9 \\
15 \\
11 \\
12\end{array}$ & $\begin{array}{c}10 \\
6 \\
15 \\
21 \\
9 \\
12 \\
12 \\
19\end{array}$ & $\begin{array}{l}1 \\
1 \\
1 \\
1 \\
1 \\
1 \\
1\end{array}$ & $\begin{array}{l}2.89 \\
1.79 \\
0.11 \\
2.84 \\
1.79 \\
0.11 \\
2.84\end{array}$ \\
\hline March 3-5, 2010; H-R & $\begin{array}{c}1130 \\
1070 \\
950 \\
900 \\
750\end{array}$ & $\begin{array}{c}10 \\
7 \\
6 \\
10 \\
5\end{array}$ & $\begin{array}{c}7 \\
9 \\
10 \\
3 \\
5\end{array}$ & $\begin{array}{l}1 \\
1 \\
1 \\
1\end{array}$ & $\begin{array}{l}0.77 \\
0.20 \\
0.70 \\
\\
3.33\end{array}$ \\
\hline August 23-27, 2010; C-D & $\begin{array}{c}1070 \\
950 \\
750 \\
590\end{array}$ & $\begin{array}{c}9 \\
20 \\
7 \\
5\end{array}$ & $\begin{array}{c}18 \\
23 \\
16 \\
6\end{array}$ & $\begin{array}{l}1 \\
1 \\
1 \\
1\end{array}$ & $\begin{array}{l}0.92 \\
2.37 \\
0.41 \\
1.56\end{array}$ \\
\hline
\end{tabular}

Editorial responsibility: Nils Chr. Stenseth, Oslo, Norway
Submitted: July 11, 2011; Accepted: January 30, 2012 Proofs received from author(s): May 25, 2012 